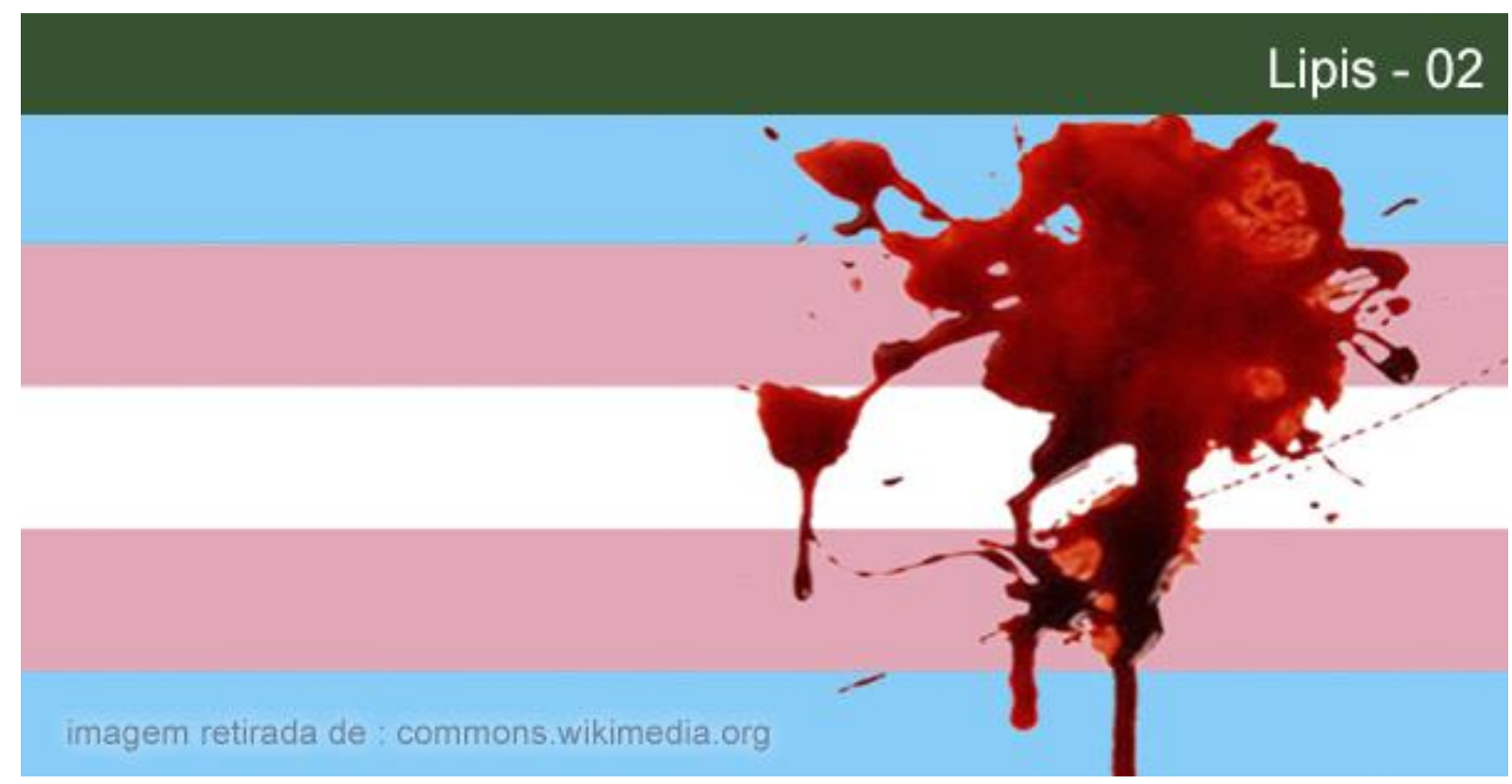

\title{
RITUAIS BRUTAIS NAS MORTES DE TRAVESTIS E TRANSEXUAIS: O QUE A ABJEÇÃO DA POPULAÇÃO T DENUNCIA?
}

\author{
Diego da Silva Santos \\ Graduado em Psicologia pela Pontificia Universidade Católica (PUC-Rio). Especialista em Gênero e Sexualidade \\ pela Universidade Federal do Rio de Janeiro (CLAM/IMS/UFRJ). Mestre em Políticas Públicas em Direitos \\ Humanos pela UFRJ. E-mail: diesantos.psicologia@gmail.com.
}

\section{Sara Wagner Pimenta Gonçalves Jr.}

Mulher travesti. Graduada em Letras pela Universidade Estácio de Sá (UNESA) e em Pedagogia pela Universidade do Estado do Rio de Janeiro (UERJ). Mestranda em Educação pela UERJ. Bolsista CNPq. E-mail: sarayork@live.com.pt.

\section{Sergio L. Baptista da Silva}

Professor Associado 1 da Universidade Federal do Rio de Janeiro (UFRJ). Doutor em Letras pela Universidade de São Paulo (USP). Lider do GE-SER (Grupo de Pesquisa Gêneros, Sexualidades e Raça em Educação - UFRJ). E-mail:serggioluiz@uol.com.br.

\section{Anna Marina B. Pinheiro}

Professora Adjunta da Universidade Federal do Rio de Janeiro (UFRJ). Doutora em História Social pela Universidade Federal Fluminense (UFF). Coordenadora do Laboratório de Estudos de Gênero - UFRJ. E-mail: annapin09@gmail.com.

Resumo: O presente artigo tem o objetivo de analisar o conceito de Abjeção, à luz de Julia Kristeva e a partir da discussão de Berenice Bento, para compreender de que forma a figura de travestis e transexuais é representada no imaginário da sociedade. Os crimes de ódio, a repulsa social e o nojo são tomados como ponto de partida para discutir abjeção social e seus sentidos. Convergindo com os pontos de reflexão de Judith Butler, Monique Wittig e Gayle Rubin, é trazida a visão da psicanálise via Lacan das fórmulas de sexuação. Conclui-se que a violência contra a população trans e travesti emerge de uma angústia pré-simbólica frente a fissura na certeza do sexo/gênero que as figuras tidas como abjetas estampam. Contudo, é importante ressaltar o apagamento dos corpos travestis e transexuais, que mesmo quando evidenciados na emergência de discursos na atualidade, são apagados na representação pela cisgeneridade.

\section{POLÊM!CA | LABORE (3:}

Polêmica - Revista Eletrônica da Uerj - Rua São Francisco Xavier, 524, $1^{\circ}$ andar bloco D, sl.1001 • Tels.: +55 21 2334-4088 / 4087 • http://www.e-publicacoes.uerj.br/index.php/polemica/index http://www.labore.uerj.br • laboreuerj@yahoo.com.br 
Palavras-chave: (Trans)Feminismos. Travesti. Transgeneridades. Diferença e Abjeção.

\title{
DEATH RITUALS OF TRAVESTIS AND TRANSGENDER PEOPLE: WHAT IS THAT SAYS?
}

\begin{abstract}
This article analyzes the concept of abjection, in the vision of Julia Kristeva and from the discussion of Berenice Bento, to understand how the figure of transvestites and transsexuals is represented in the imaginary of society. The crimes of hatred, social repulsion and disgust are taken as a starting point to discuss social abjection and its senses. Converging with the points of reflection of Judith Butler, Monique Wittig and Gayle Rubin, the vision of the psychoanalysis by Lacan and the graphs of sexuation has been brought to. It is concluded that the violence against the trans and transvestite population has born of pre-symbolic anguish against the fissure in the certainty of the sex/gender that the figures considered as abject stammer. However, it is important to highlight the erasure of transvestite and transsexual bodies, which even when evidenced in the emergence of discourses today are erased in the representation by cisgenerity.
\end{abstract}

Keywords: (Trans)Feminism. Travesti. Transgender. Diference e Abjection.

\section{Introdução}

O Brasil matou mais de 868 travestis e transexuais nos últimos 8 anos, segundo dados conferidos por organizações de apoio como ANTRA - Associação Nacional de Pessoas Trans e Travestis e IBTE - Instituto Brasileiro Trans de Educação. Entretanto, há subcasos ou casos deslocados, como quando a pessoa trans é tratada como gay ou lésbica cisgênera e o dado se perde, ou por falta de comunicação, seja por parte da família ou pessoas próximas. Esse dado que traz as mortes em nível mundial foi publicado pela ONG TGEu - Transgender Europe (BALZER; LaGATA; BERREDO, 2016) no final de 2016, e mesmo sendo alarmante, assustador e revoltante, infelizmente não é novidade para uma parcela quase invisibilizada da sociedade brasileira; um grupo de pessoas que precisa resistir à exclusão e à violência cotidiana. Segundo levantamento divulgado pelo Grupo Gay da Bahia (MADEIRO, 2017), foram registrados 277 homicídios até 20 de setembro de 2017, a maior média de assassinatos desde que os dados passaram a ser contabilizados pela entidade baiana, que também anuncia no final de 2018 o fim de seus levantamentos em razão da não obtenção de voluntários para esta produção. De acordo com o relatório da ANTRA (2019) e IBTE, entre janeiro e dezembro de 2018 ocorreram 162 assassinatos de Travestis, Mulheres Transexuais e Homens Trans. Em 2019, até 12 de outubro, foram 96 assassinatos registrados segundo o mapa de assassinatos alimentado pela ANTRA (2019). O Brasil se mantém, assim, na primeira posição, como o país com mais registros de homicídios, do ranking anual que contabiliza a transfobia sofrida por essa população.

Jacqueline Gomes de Jesus (2013) realiza uma caracterização dos assassinatos de travestis e de mulheres e homens transexuais no Brasil, em nível micro, como crimes de ódio,

\section{POLÊM!CA $\mid$ LABORE}

Polêmica - Revista Eletrônica da Uerj - Rua São Francisco Xavier, 524, $1^{\circ}$ andar bloco D, sl.1001 • Tels.: +55 21 2334-4088 / 4087 • http://www.e-publicacoes.uerj.br/index.php/polemica/index http://www.labore.uerj.br • laboreuerj@yahoo.com.br 
e em nível macro, como parte de uma tentativa de genocídio dessa população. Seu objetivo é categorizar essa violência como estrutural e destacar as suas consequências como estratégia de retirar da invisibilidade o sofrimento $\mathrm{T}$, revelando o recurso da violência como um mecanismo de intolerância generalizada, que reivindica a ideia da impossibilidade de conviver com esse outro, abjeto, porque sua vivência de gênero é diferente da hegemônica.

Essas mortes ocorrem diariamente e quase nunca são alvo de alarde por parte da mídia ou mesmo de comoção social, quiçá nacional - salvo um ou outro caso, como da Travesti Dandara, que tomou a internet em um alvoroço no início de 2017 com o crime filmado e divulgado. Não se vê uma reverberação desta indignação na população de forma efetiva e contínua; a indignação surge efêmera, não capaz de promover mudança social a ponto de evitar que uma nova travesti seja brutalmente assassinada e tenha sua morte filmada e compartilhada na internet. Outro caso ocorreria meses depois e já não é o primeiro, logo sem grande eloquência; era o de Niely Lafontayne (ABREU, 2017). A despeito dos requintes de crueldade terem sido ainda mais grotescos, esse e outros casos sequer geraram algum tipo de comoção maior ou igual a do caso de Dandara.

A marcação "o Brasil matou”, como se fosse um bloco único, serve para explicitar uma opinião quase hegemônica de parte da população, trazendo a responsabilidade dessas mortes para o sistema da cisgeneridade, do qual todos os não transgêneros, não travestis, não transexuais ou intersexos não mutilados participam. Para Jesus (2012), cisgênero é "um conceito que abarca as pessoas que se identificam com o gênero que lhes foi determinado no momento de seu nascimento" (p. 15). Cisgeneridade é, então, a concordância entre a identidade de gênero e o sexo biológico de um indivíduo e o seu comportamento ou papel considerado socialmente aceito para esse sexo.

Sobre a cisgeneridade, tal como a heterossexualidade, pouco se estuda, pouco se esmiúça, em comparação aos estudos sobre a transgeneridade. Recentemente, Viviane Vergueiro (2015), mulher trans, tem desenvolvido pesquisas sobre o conceito:

Considerar a cisgeneridade e a cisnormatividade deve estar atrelado, assim, a uma percepção crítica destes projetos coloniais como limitadores e desumanizadores de um amplo espectro de corpos, identificações e identidades de gênero não normativas, para muito além dos conceitos ocidentalizados de gênero. É importante ter em mente, assim, que as identidades trans, no geral, são produzidas no interior de contextos ocidentalizados - como, por exemplo, a categoria transexual, produzida a partir dos discursos médicos articulados com epistemologias eurocêntricas. Desta forma, estes projetos podem ser pensados em suas articulações com o biopoder, no sentido de “[ [...

\section{POLÊM!CA $\mid$ LABORE}

Polêmica - Revista Eletrônica da Uerj - Rua São Francisco Xavier, 524, $1^{\circ}$ andar bloco D, sl.1001 • Tels.: +55 21 2334-4088/4087 • http://www.e-publicacoes.uerj.br/index.php/polemica/index http://www.labore.uerj.br • laboreuerj@yahoo.com.br 
o discurso da ciência sexual [ser] íntima e indissociavelmente ligado à noção de uma "verdade" que [...] se organiza como um porto seguro às estratégias de biopoder" (LEITE JR., 2011, p. 196). E, neste sentido, acredito que seja possível tomar este exercício como uma genealogia transfeminista sobre a produção de inteligibilidade sobre corpos generificados, uma genealogia que, ao partir da consideração (ainda em disputa) de que pessoas de corpos e gêneros inconformes possuem existências e gêneros legítimos, tem desde aí uma fundação importante para desconstruir ideias deterministas e binárias sobre gêneros (VERGUEIRO, 2015, p. 48).

A norma não se classifica e apenas o que foge desta norma, que foge ao que faz parte do padrão, é que captura nossa atenção - não só atenção, mas a noção de controle. Berenice Bento (2006) foi uma das primeiras vozes a se erguer contra a despatologização das identidades divergentes de gênero, ao denunciar como a psicologia, a psiquiatria e a medicina exercem uma relação de saber-poder e ditos de verdade sobre o gênero e a sexualidade, a ponto de normatizar, controlar e ditar sobre a vida e as formas de viver dessa população.

A investigação a que nos propusemos aborda os seguintes questionamentos: por que essas mortes acontecem, da forma brutal que acontecem, e quais processos desaguam nessa espécie de anuência social? Por que travestis, transexuais, transgêneros e pessoas intersexo são alvo de tamanha ojeriza social? O que elas denunciam à sociedade cisgênero só por existirem?

Proporcionalmente às políticas de ampliação, está a política do demérito exercida nas redes sociais de modo legitimador, o que Butler (2013) questiona quando pergunta quais os corpos que importam; quais são os dignos de nossa dor e de nossas lágrimas.

É no conforto de nossas casas, no aconchego de nossos sofás que vemos diante de nossos olhos o ódio ao diferente; aquilo que Gonçalves Jr. (2018) chama de diferentefóbico apenas se expõe em nossas redes sociais. Em 2017, uma subcelebridade ganhou notoriedade ao ter sua postagem, de alguns anos passados, trazida à tona - e junto a verdade de sua ação e desejo junto à comunidade trans.

\section{POLÊM!CA $\mid$ LABORE}

Polêmica - Revista Eletrônica da Uerj - Rua São Francisco Xavier, 524, $1^{\circ}$ andar bloco D, sl.1001 • Tels.: +55 21 2334-4088/4087 • http://www.e-publicacoes.uerj.br/index.php/polemica/index http://www.labore.uerj.br • laboreuerj@yahoo.com.br 
Figura - 1: O nojo e a abjeção no tweet de Biel

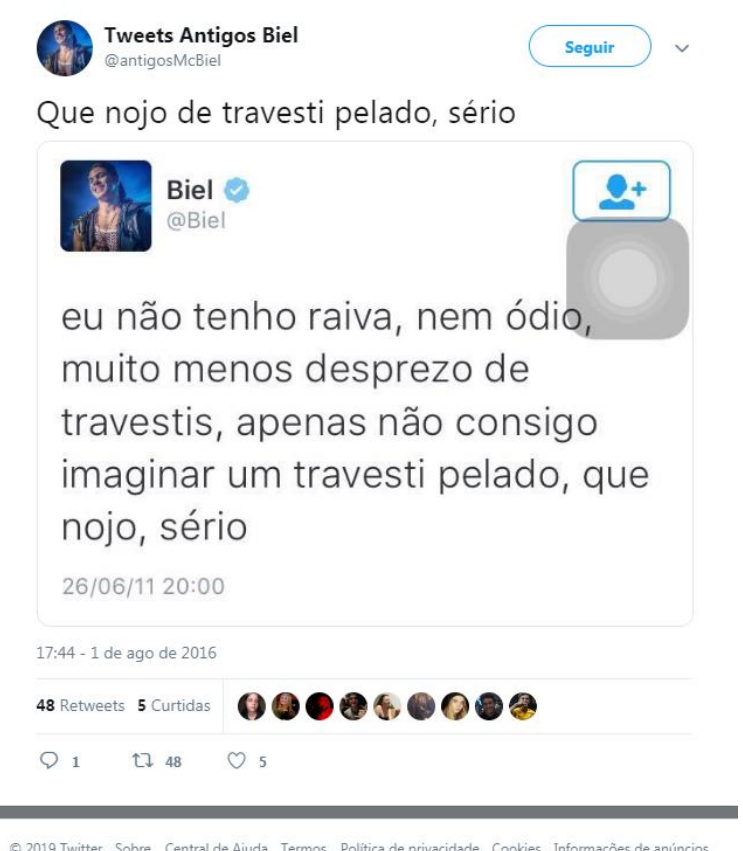

Fonte: Tweets Antigos Biel (2016).

O tweet acima pertence ao referido cantor de funk. Outro caso, fica exposto no texto abaixo, que foi retirado de um fórum da internet (YAHOO, 2014), com data do ano de 2014, reproduzido integralmente:

Transei com um travesti e sinto nojo de mim mesmo. O que fazer ???

Sempre me relacionei com mulheres, já tive cerca de 4 namoradas, ficantes e nunca havia tido relações com um "homem". Terminei um relacionamento longo de 04 anos mas ele teve fim (foi um final tranquilo onde ambos chegaram na conclusão de que devia ter terminado) perdi meu cão 1 mês antes que era meu companheiro, fora isso trabalho quase o dia todo e me afoguei nele para tentar levar a vida, porém, comecei a ir em diversos puteiros. Comecei a me culpar e a tentar parar, porém, não conseguia, numa dessas tentativas (de parar com os puteiros) havia um travesti na rua do meu trabalho, MUITO parecido com uma mulher, diria até mesmo bonita/o e após 03 semanas me contendo de vontade de fazer sexo acabei pagando para fazer com ele/a. Depois disso me arrependi profundamente, senti nojo de mim mesmo (obs: não sou homofóbico, tenho amigos que são gays, lésbicas e outros héteros), não acreditei que tinha feito aquilo, ao "pegar" esse travesti entrei em conflito comigo mesmo mas fui até o fim, fui o ativo da relação mas não consigo me perdoar. Estou fazendo terapia mas não consigo tirar isso da cabeça, já tive até ideias de suicídio. Não sei como encarar uma nova mulher.... mas sei que se contar isso para ela muito provavelmente elá terá nojo de mim também e posso botar tudo a perder. (Anônimo).

O significante "nojo" é uma palavra forte, que curiosamente salta aos olhos. Emerge dela um sentido pungente. O que seria aquilo que nos provoca nojo, asco? Algo tão nocivo que

\section{POLÊM!CA $\mid$ LABORE}

Polêmica - Revista Eletrônica da Uerj - Rua São Francisco Xavier, 524, $1^{\circ}$ andar bloco D, sl.1001 • Tels.: +55 21 2334-4088 / 4087 • http://www.e-publicacoes.uerj.br/index.php/polemica/index http://www.labore.uerj.br • laboreuerj@yahoo.com.br 
o mero contato, pensamento, aproximação excessiva ou troca de fluidos corporais conduz à ideia do suicídio? Comumente, algo da ordem do grotesco, do inaceitável, marcado por algum critério moral impresso apenas para o contato com aquela pessoa. Como diz Julia Kristeva (1982), é da ordem de algo que o domínio da linguagem não é capaz de encontrar palavras que, sozinhas, deem conta de expressar a sensação de repulsa. Desse modo, segundo a autora, o significante nomeia uma reação corporal incontrolável frente aquilo que não se é capaz de elaborar. É neste ponto que o corpo reage. Então, por serem condenáveis (moralmente) por suas práticas, os transgressores das regras do não relacionamento "gay" são pegos por uma aparência que alimenta o desejo e fantasia: a exotificação da mulher trans. Em seguida, após seu uso, consumo (como quem usa uma droga, no escuro e no calabouço moral) e fim do prazer, resta a repulsa moral dos dogmas, crenças e atitudes proibidas. É o limiar do desejo e da repulsa, os limites dessa pulsão.

Bento (2017), ao questionar acerca dos sujeitos eleitos como 'novos sujeitos' da contemporaneidade e ao evidenciar como estes não são novos, mas que, na realidade, ocupam a posição de abjetos frente aos tradicionais objetos de estudos sociológicos, elege a abjeção como potente categoria heurística nos estudos voltados à compreensão de qual é o lugar reservado socialmente aos corpos sem inteligibilidade social. Para Bento (2017), os corpos trans, travestis, transgêneros e intersexo encontram-se ininteligíveis e, no que se refere à abjeção,

[...] podemos pensa-la como um conjunto de práticas reativas, hegemonicamente legitimadas, que retira do sujeito qualquer nível de inteligibilidade humana. Os atributos considerados qualificadores para os corpos entrarem no rol de "seres humanos" não encontram morada quando se está diante de uma pessoa na qual o aparato conceitual de que se dispõe para a significação da existência humana não a alcança. A linguagem entra em pane, em colapso. E, nessa falta de "texto", o nojo, a violência se instauram. Acho que essa sociologia das abjeções não é de difícil compreensão em uma sociedade que vive as chagas de um passado de quase 400 anos de escravidão. A abjeção deve ser pensada cultural, política e historicamente. (BENTO, 2017, p. 50, grifo nosso).

Bento defende a tese de que o silêncio da sociologia em torno da existência de pessoas travestis, transexuais, trangêneros e intersexo por tanto tempo possui um paralelo com as condições de vida desumanizadoras. A luta e a disputa constante das pessoas abjetas é para ampliar os significados e atributos do que é ser humano. Em última análise, tais corpos lutam para serem reconhecidos como humanos. A mesma luta que, defendia Fanon (2008), pessoas

\section{POLÊM!CA $\mid$ LABORE}

Polêmica - Revista Eletrônica da Uerj - Rua São Francisco Xavier, 524, $1^{\circ}$ andar bloco D, sl.1001 • Tels.: +55 21 2334-4088/4087 • http://www.e-publicacoes.uerj.br/index.php/polemica/index http://www.labore.uerj.br • laboreuerj@yahoo.com.br 
negras empreendiam. A própria ciência social não direcionaria esforços àquilo que não é humano, deixando a cargo das ciências médicas e da psicologia a responsabilidade de estudar o inumano.

Bento (2017) dialoga com Spivak (2010) quando afirma que os subalternos não podem ser representados. O sujeito subalterno na definição de Spivak (2010) é aquele pertencente "às camadas mais baixas da sociedade constituídas pelos modos específicos de exclusão dos mercados, da representação política e legal, e da possibilidade de se tornarem membros plenos no estrato social dominante" (p. 12). A autora indiana desenvolve o conceito de violência epistêmica, na qual reside uma ferramenta de neutralização do outro, sendo este outro um subalterno ou um colonizado, invisibilizado, desapropriado de qualquer possibilidade de representação, silenciado, emudecido. Ainda segundo a autora, esse silêncio marginal da ciência diz muito sobre a vida dos sujeitos.

Abjeção é um termo discutido em profundidade por Kristeva (1982) e debatido posteriormente de forma interessante por Butler (2000). Em Powers of Horror: an essay on abjection $^{1}$ (1982), Kristeva usa o termo abjeção para descrever a situação complexa do sujeito que não é simplesmente alienado, mas que é "radicalmente excluído" e atraído "para o local onde o significado deixa de existir" (p. 1).

Para ela, o abjeto inclui qualquer um que seja alienado da sociedade: imigrantes, negros, mas também homossexuais e transexuais, mães solteiras, criminosos e doentes mentais. A autora usa a imagem do cadáver - que uma vez foi uma pessoa, mas já não é - para descrever o status do abjeto. Não totalmente reconhecido como um sujeito (uma pessoa), o abjeto habita um mundo obscuro de existência parcial. A autora demonstra que a ideia de abjeção se manifesta de forma mais concreta quando nos deparamos com possibilidades ou concretudes indesejáveis inerentes à nossa existência, como a morte, por exemplo (KRISTEVA, 1982, p. 4).

Há, na abjeção, para Kristeva (1982), revoltas de um ser contra aquilo que o ameaça e que lhe parece vir de um fora ou de um dentro que é exorbitante. Essa ameaça solicita o sujeito, inquieta e fascina, um desejo que não se quer deixar seduzir. Enojado, o sujeito rejeita, regurgita. Esse outro é um lugar tão tentador quanto condenado. Como um polo de atração e de repulsa, coloca aquele no qual tais sentidos habitam, literalmente fora de si. O objeto, fazendo oposição, nos equilibra na trama frágil de um desejo de sentido que, de fato, liga

\footnotetext{
${ }^{1}$ Poderes do horror: um ensaio sobre abjeção em tradução livre.

\section{POLÊM!CA | LABORE}

Polêmica - Revista Eletrônica da Uerj - Rua São Francisco Xavier, 524, $1^{\circ}$ andar bloco D, sl.1001 • Tels.: +55 21 2334-4088 / 4087 • http://www.e-publicacoes.uerj.br/index.php/polemica/index http://www.labore.uerj.br • laboreuerj@yahoo.com.br
} 
indefinidamente, infinitamente ao abjeto que é radicalmente um excluído e nos lança num local onde o sentido desmorona. O interesse e agrado são prévios para satisfação e então a culpa e a repulsa emergem dadas suas fontes morais.

A abjeção em Kristeva (1982) seria, sobretudo, ambiguidade. Ao demarcar ela não separa radicalmente o sujeito daquilo que o ameaça - pelo contrário, ela o reconhece em uma situação de perigo perpetuada. A abjeção é um misto de julgamento e afeto, de condenação e de efusão, de signos e de pulsões. Da violência com a qual um corpo se separa de um outro para ser - a separação materna mãe-bebê -, a abjeção conserva em si aquela memória na qual se perde o contorno da coisa significada e em que só atua o afeto imponderável - sem linguagem concreta, senão no campo das subjetividades. Se somos afetados por aquilo que não nos aparece ainda como uma coisa, é porque as leis, as relações, as estruturas de sentido nos governam e nos condicionam para tal.

Para esta autora, cabe então dirigir-se ao abjeto para excluí-lo daquilo que não será, para o indivíduo, um mundo assimilável. Evidentemente, esse sujeito é como qualquer outro, participante da lógica mimética que cria e reitera o $\mathrm{Eu}$, dos objetos e dos signos. Mas quando o Eu (se) busca, (se) perde, ou goza, então o "Eu" é heterogêneo e não homogêneo, pela multiplicidade de escolhas objetais.

O que Kristeva explica é que o abjeto é aquilo que se encontra fora da relação sujeito/objeto, fora da ordem do simbólico, é um significado sem significante. Nas palavras de Kristeva: "toda abjeção é, na verdade, um reconhecimento da falta sobre a qual qualquer ser, sentido, linguagem ou desejo se fundamenta" (KRISTEVA, 1982, p. 5). Ao depararmo-nos com um cadáver, somos levados a pensar em nossa própria morte, que é um fato inescapável da existência, porém, algo que não queremos assimilar.

Ou seja, até aqui, é possível perceber que as teorizações de Kristeva trazem luz ao funcionamento psíquico quando, frente ao corpo que borra a certeza do gênero naturalizada no sexo, não encontra outra saída senão a violência. O que estrutura o Eu é justamente o controle do abjeto, que se manifesta corporalmente pelo nojo.

Outra manifestação do abjeto consiste em nossos dejetos e fluidos corporais que nos geram nojo, mas que são por nós mesmos produzidos, portanto, parte de nós. O abjeto seria aquilo que existe dentro de nós, que faz parte de nossa existência, mas que não queremos reconhecer como tal. É algo da ordem do não nomeado, é pré-linguístico. Abjeção é pré-

\section{POLÊM!CA $\mid$ LABORE}

Polêmica - Revista Eletrônica da Uerj - Rua São Francisco Xavier, 524, $1^{\circ}$ andar bloco D, sl.1001 • Tels.: +55 21 2334-4088 / 4087 • http://www.e-publicacoes.uerj.br/index.php/polemica/index http://www.labore.uerj.br・ laboreuerj@yahoo.com.br 
simbólica. Um exemplo é o simples fato de, no pós gozo, algumas pessoas terem repulsa pelo sêmen.

Kristeva vem da psicanálise, mesma fonte da crítica de Bento quanto à patologização das identidades trans, travestis, transgêneros e intersexos; e mesma fonte de diálogo promovido por Judith Butler (2000; 2013), Monique Wittig (2006) e Gayle Rubin (1993). Julgamos proveitoso uma breve explanação sobre um constructo teórico psicanalítico - as fórmulas da sexuação - que complementam possíveis teorizações sobre os motivos dessa violência brutal contra a população $\mathrm{T}$.

\section{A sexuação}

Antônio Quinet (2013) tenta fazer uma aproximação da categoria teórica "gênero" com a conceituação psicanalítica de modalidade de gozo, constructo psicanalítico utilizado para representar o binarismo masculino e feminino no registro do inconsciente e da psiquê. $\mathrm{O}$ autor mostra, por meio de seus estudos de Lacan e do quadro de fórmulas da sexuação, que o pertencimento de um lado da partilha dos sexos se define pela escolha do gozo e isso seria independente da escolha objetal. No sentido freudiano (FREUD, 1905/1969), o desvio é a inversão sexual, ou seja, as possibilidades da Homo/Bi/Heterossexualidade. Mas posição sexuada e escolha de objeto sexual são de âmbitos totalmente distintos. Estar numa posição masculina ou feminina de gozo é uma coisa, ter um homem ou uma mulher como objeto sexual é outra e não são posições excludentes.

Segundo Lacan (1972-73/1985), conforme citado por Bonfim (2014), qualquer ser falante se inscreve de um lado ou do outro do quadro, visto que os matemas revelariam que "Tais são as únicas definições possíveis da parte dita homem ou bem mulher para o que quer que se encontre na posição de habitar a linguagem" (LACAN, 1972-73/1985, p. 107). A coluna esquerda da imagem abaixo descreve a posição masculina e o lado oposto, a feminina. Esta divisão não corresponde à distinção anatômica entre os sexos, mas, sim, uma posição sexuada determinada no próprio discurso do sujeito, muitas vezes em dissonância com sua anatomia (BONFIM, 2014).

\section{POLÊM!CA $\mid$ LABORE}

Polêmica - Revista Eletrônica da Uerj - Rua São Francisco Xavier, 524, $1^{\circ}$ andar bloco D, sl.1001 • Tels.: +55 21 2334-4088 / 4087 • http://www.e-publicacoes.uerj.br/index.php/polemica/index http://www.labore.uerj.br • laboreuerj@yahoo.com.br 
Figura - 2: Fórmulas da sexuação segundo Lacan

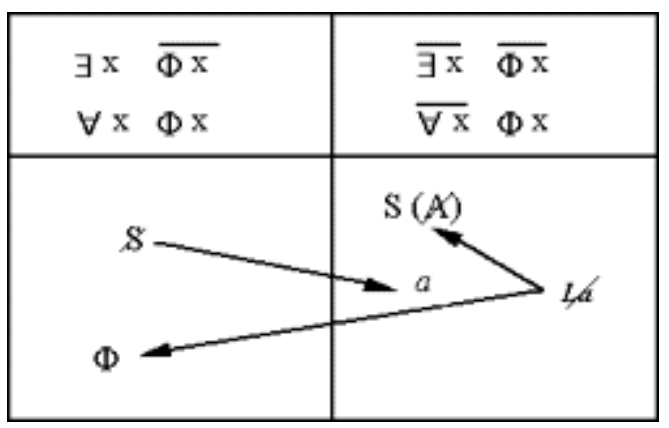

Fonte: Lacan (1972-73/1985, p. 105).

Ou seja, ter pênis ou vagina não garante naturalmente que o indivíduo pertença a qualquer uma das posições (QUINET, 2013). Segundo a noção de partilha dos sexos, é nela que se escolhe a posição sexuada: é dito "homem" aquele que se encontra inteiramente submetido à função fálica ( $O$ todo fálico - Фx). A partilha dos sexos pode ser lida como 'o todo' e 'o não todo’ em relação à função fálica. O ‘todo' é ligado ao gozo fálico, que é próximo do gozo sexual propriamente dito; o não todo é o gozo do Outro, inefável, para além do falo e, portanto, também da sexualidade, mas não sem um prazer externo (QUINET, 2013).

Lacan (apud CATÃO, 2013) escreveu as fórmulas: existe ao menos um homem para quem a função fálica não incide e para todo homem é verdadeiro que a função fálica incide. Priscila de Lima Catão (2013) explica que a primeira delas foi baseada no mito freudiano do pai primevo de Totem e Tabu: era uma tentativa de dar conta do marco mítico que dividiria a natureza e a cultura, na qual o líder da horda primitiva teria livre acesso a todas as mulheres do bando sem nenhuma lei que lhe proibisse e concomitantemente impediria o acesso dos outros machos às mulheres. $\mathrm{O}$ assassinato deste pai é logo seguido pela instauração de uma lei da proibição do incesto, pois os filhos, movidos pelo remorso e pelo sentimento de culpa, em reverência a este pai, criam a lei simbólica - erguem, então, o Totem. A função fálica (Фx) remeteria à castração. Assim, a fórmula é: existe pelo menos um homem que não foi submetido à castração, ou seja, o pai primevo (Deus - o patriarcado). Esse "pelo menos um" que não segue a regra da castração permite a fundamentação dela e, desta forma, a exceção exige a regra. A universalidade expressa na segunda fórmula só tem sentido, portanto, porque pelo menos um elemento se subtrai dela. Assim se resume a linha inferior do lado masculino, trazendo a fórmula proposicional que ilustra essa universalidade: "para todo homem é verdadeiro que a função fálica incide" (CATÃO, 2013).

\section{POLÊM!CA $\mid$ LABORE}

Polêmica - Revista Eletrônica da Uerj - Rua São Francisco Xavier, 524, $1^{\circ}$ andar bloco D, sl.1001 • Tels.: +55 21 2334-4088 / 4087 • http://www.e-publicacoes.uerj.br/index.php/polemica/index http://www.labore.uerj.br • laboreuerj@yahoo.com.br 
No lado feminino, Catão (2013) explica que as duas fórmulas seriam: não existe ao menos uma mulher para quem a função fálica não incide e para não-toda mulher é verdadeiro que a função fálica incide. Bonfim (2014) ressalta que o quantificador existencial é negado (não existe $\mathrm{x}$ ), bem como é negada a função (a função fálica não incide). $\mathrm{O}$ lado direito do quadro mostra a não existência de pelo menos um que tenha escapado à castração, ou seja, não existe ao menos uma mulher que seja uma exceção à regra (CATÃO, 2013). Consequentemente, a não existência da exceção não constrói a regra universal para todas as mulheres. Se para o lado masculino, a exceção funda a regra, com a ausência de uma exceção, a universalidade (x), o 'para todo x' não se aplica:

\begin{abstract}
O conjunto universal só pode ser fundado na presença de um que esteja fora da regra do 'todo', assim, se do lado feminino não há essa exceção, a universalidade do ponto de vista da função fálica é inviabilizada, ou seja, é impossível falar de 'todas as mulheres' e não haveria "A Mulher", numa categoria universal afirmativa, donde se produz as famosas frases "a mulher não existe" e "a mulher é não-toda" (CATÃO, 2013, p. 03).
\end{abstract}

Quinet (2013) comenta que a escolha da posição sexuada não é garantida. Ainda que pareçam estar divididos homens para um lado e mulheres para outro, isso não é uma regra somos sempre responsáveis por nossa escolha de posição enquanto seres sexuados. Nada impede que um homem, inscrevendo-se do lado do todo fálico (gênero masculino), tenha uma escolha de objeto homossexual. "Posição sexuada e escolha de objeto são de âmbito totalmente distinto. Estar na posição feminina ou masculina é uma coisa; ter um homem ou uma mulher como objeto sexual é outra" (QUINET, 2013, p. 133). O sistema sexo-gênero não seria submetido a uma heterossexualidade compulsória (RUBIN, 1993).

Embora Lacan (1972-73/1985) utilize-se do termo ser falante sem endossar a dicotomia macho/fêmea, oriunda da descrição biológica dos órgãos genitais, como norteadora do entendimento psicanalítico, essa dicotomia estava latente em Freud (1905/1969) em seus primeiros escritos sobre essa teorização da sexualidade. Ao explicarmos pela via do significante a diferença dos sexos, em Lacan, com auxílio dos autores citados anteriormente, nos esforçamos para ir para além da noção freudiana inicial da partilha dos sexos, com o pênis como divisor de águas, por meio do qual caberia ao homem a angústia de castração e à mulher a inveja do pênis, no sentido de a ele não estar referenciada e ao pênis como suporte imaginário do falo, ou do poder na sociedade. A anatomia responde com os caracteres do corpo, a fisiologia dos sexos, os hormônios. A sociedade responde com as regras sociais, modos de se vestir, modos de desejar,

\title{
POLÊM!CA $\mid$ LABORE
}

Polêmica - Revista Eletrônica da Uerj - Rua São Francisco Xavier, 524, $1^{\circ}$ andar bloco D, sl.1001 • Tels.: +55 21 2334-4088/4087 • http://www.e-publicacoes.uerj.br/index.php/polemica/index http://www.labore.uerj.br • laboreuerj@yahoo.com.br 
ditando como homens e mulheres devem se comportar segundo seu gênero - ela, a sociedade, constrói os “semblantes Homem e Mulher" (QUINET, 2013, p. 135).

Mas, se nos aprofundarmos um pouco nas discussões teóricas pós-lacanianas, logo percebemos que as fórmulas da sexuação falam sobre gozo - gozo fálico e não-todo (real) - e não possuiriam relação com gênero porque esta construção teórica seria da ordem do Imaginário se unido ao Simbólico. O gozo lacaniano se reveste do semblante, que nada mais é do que um discurso Imaginário + Simbólico. Não existe gozo cru, já que é necessário sempre o suporte da linguagem, da fantasia. O gozo cru seria o próprio corpo despedaçado antes mesmo do estádio do espelho (LACAN, 1966/1998). Freudianamente, as zonas erógenas na sexualidade perversapolimorfa (FREUD, 1905/1969).

Contudo, ao entendermos a sociedade que se estratifica e se congela numa concepção de mundo dual e binária, o desespero que toma o encontro com o outro abjetado, o outro que borra as bordas seguras do semblante Homem e Mulher, gera a reação não-simbolizada, o nojo e a violência. Para abordarmos tal ponto, é interessante trazer ao debate Judith Butler. Na próxima seção, abordaremos a contribuição da autora para o debate sobre Abjeção. Muitas críticas das teorias de gênero e de feministas buscam ir além das teorias baseadas na oposição homens vs. mulheres e, também, aprofundar os estudos sobre minorias sexuais (gays e lésbicas, travestis, transexuais, transgêneros e intersexo), dando maior atenção aos processos sociais amplos e relacionados que sexualizam a sociedade como um todo de forma a heterossexualizar e/ou homossexualizar instituições, discursos e direitos.

\section{A performatividade e algumas teorias de gênero pós-estruturalistas}

Gayle Rubin (1993) cita que sua leitura de determinados textos psicanalíticos é filtrada pela lente fornecida por Lacan, cuja interpretação da escritura freudiana também percebe ter sido fortemente influenciada por Lévi-Strauss. Para Rubin, o psicanalista francês insiste que Freud nunca pretendeu dizer nada sobre anatomia e que a teoria do pai da psicanálise era sobre a linguagem e os significados culturais justamente impostos à anatomia. $\mathrm{O}$ debate sobre a verdade da teoria psicanalítica é um ponto em disputa pelas escolas de psicanálise, contudo, Rubin faz o esforço de tentar reformular a teoria clássica da feminilidade na terminologia lacaniana.

\section{POLÊM!CA $\mid$ LABORE}

Polêmica - Revista Eletrônica da Uerj - Rua São Francisco Xavier, 524, $1^{\circ}$ andar bloco D, sl.1001 • Tels.: +55 21 2334-4088 / 4087 • http://www.e-publicacoes.uerj.br/index.php/polemica/index http://www.labore.uerj.br • laboreuerj@yahoo.com.br 
Para Rubin (1993), na visão de Lacan, a crise edipiana nada mais é do que a situação na qual a criança aprende as regras sexuais implícitas nos termos relacionados à família e aos parentes. Édipo seria a compreensão do sistema e do lugar que a criança ocupa e a sua resolução se dá quando a criança aceita esse lugar, ali conformando-se. "Ainda que a criança recuse seu lugar, não lhe é possível deixar de conhecê-lo. Antes da fase edipiana, a sexualidade da criança é lábil e não muito bem estruturada. Cada criança encerra todas as possibilidades sexuais passíveis de expressão humana" (RUBIN, 1993, p. 16).

Segundo a autora, na terminologia freudiana, o complexo de Édipo apresenta duas alternativas à criança: ter um pênis ou ser castrada. Já na teoria lacaniana do complexo de castração é abandonada qualquer referência à realidade anatômica; a alternativa que se oferece à criança pode ser reformulada: ter ou não ter um falo. Castração é não ter o falo (no registro do simbólico). A castração não seria, então, uma "falta" verdadeira de uma genitália, mas um significado atribuído aos genitais de uma mulher. O falo passa a ser um traço distintivo que define quem é castrado (todo referido à falta) ou não-castrado (não-todo referido à falta).

A conclusão de Rubin (1993) é que a presença ou ausência do falo é a base de diferenças entre dois status sexuais: homem e mulher. As diferenças são hierarquizadas e o falo significa a dominação dos homens sobre as mulheres. Com isso, a autora infere que a inveja do pênis freudiana é um reconhecimento disso:

[...] na medida em que os homens têm direitos sobre as mulheres que estas não têm sobre si mesmas, o falo também é um símbolo da diferença entre "o que troca" e "o que é trocado", entre o presente e aquele que o dá. Ao fim e ao cabo, nem a teoria clássica freudiana do processo edipiano nem sua versão lacaniana fazem sentido, a menos que perdurem entre nós as relações de sexualidade paleolíticas. Ainda vivemos numa cultura "fálica". (RUBIN, 1993, p. 16-17).

Para Butler (2000), gênero antecede sexo, é o que dá sentido à ele. Para ela, partimos do princípio que gênero é expressão do sexo, mas o olhar que enquadra o sexo no gênero é da ordem do pré-discursivo. Os signos culturais do gênero fazem os sujeitos na medida em que eles são feitos também por esses sujeitos.

A partir das concepções de Michel Foucault sobre poder e biopolítica, Butler (2013) situa "gênero" numa dimensão política. Ela propõe a ideia de que gênero é um ato intencional e performativo diário, algo que Bento reafirma (2017, p. 145). São palavras ou gestos que, ao serem expressos, criam uma realidade. Esses atos, repetidos de uma forma estilizada, produzem um efeito ontológico, levam a crer na existência de seres homens e seres mulheres, produzindo

\section{POLÊM!CA $\mid$ LABORE}

Polêmica - Revista Eletrônica da Uerj - Rua São Francisco Xavier, 524, $1^{\circ}$ andar bloco D, sl.1001 • Tels.: +55 21 2334-4088/4087 • http://www.e-publicacoes.uerj.br/index.php/polemica/index http://www.labore.uerj.br • laboreuerj@yahoo.com.br 
uma ilusão de substância. Não há “ser”, não há um "fazedor”, não há um “agente” por trás do ato, não há unidade. O caráter ilusório do gênero é denunciado quando ocorre uma incapacidade de repetir, uma deformidade ou quando se trata de uma repetição parodística. Os gêneros são performances sociais, aquilo que a psicanálise chamaria de semblante a partir da posição de gozo (QUINET, 2013). Não há originais e nem cópias.

É interessante ressaltar que Butler (2013) reforça que a aparente cópia não se explicaria com referência a uma origem. É possível pensar aqui nas figuras das Dragqueens. A origem perde o sentido porque o "homem" e a "mulher" de "verdade" têm de assumir o gênero da mesma forma: por intermédio da reiteração de atos diariamente. Caso fujam dessa performance diária, sofrem sanções sociais violentas (vide os noticiários tomados de notícias sobre agressões direcionadas a pessoas heterossexuais apenas por terem parecido homossexuais).

Por meio da ideia de "performatividade", gêneros dominantes e não-dominantes (os que não se enquadram como "gêneros inteligíveis") se encontrariam no mesmo patamar, desfazendo-se a necessidade de coerência interna às identidades sexuais e da classificações dessas identidades em graus de normalidade e/ou patologia (PORCHAT, 2007).

A formação de um sujeito, para Butler (2000), exige a identificação com o fantasma normativo do sexo: essa identificação ocorre através de um repúdio que produz um domínio de abjeção, um repúdio sem o qual o sujeito não pode emergir:

\footnotetext{
Submetido ao gênero, mas subjetivado pelo gênero, o "eu" não precede nem segue o processo dessa generificação, mas emerge apenas no interior das próprias relações de gênero e como a matriz dessas relações. [...] Estas atribuições ou interpelações alimentam aquele campo de discurso e poder que orquestra, delimita e sustenta aquilo que pode legitimamente ser descrito como "humano". Nós vemos isto mais claramente nos exemplos daqueles seres abjetos que não parecem apropriadamente generificados; é sua própria humanidade que se torna questionada. Na verdade, a construção do gênero atua através de meios excludentes, de forma que o humano é não apenas produzido sobre e contra o inumano, mas através de um conjunto de exclusões, de apagamentos radicais, os quais, estritamente falando, recusam a possibilidade de articulação cultural. Portanto, não é suficiente afirmar que os sujeito humanos são construídos, pois a construção do humano é uma operação diferencial que produz o mais e o menos "humano", o inumano, o humanamente impensável. Esses locais excluídos vêm a limitar o "humano" com seu exterior constitutivo, e a assombrar aquelas fronteiras com a persistente possibilidade de sua perturbação e rearticulação. (BUTLER, 2000, p. 116-117).
}

Butler termina seu texto (2000) se perguntando quais os questionamentos a figura excluída e abjeta produz relativos à hegemonia simbólica; e também qual sua influência numa rearticulação do que pode ser legitimamente considerado como corpos que pesam, que

\section{POLÊM!CA $\mid$ LABORE}

Polêmica - Revista Eletrônica da Uerj - Rua São Francisco Xavier, 524, $1^{\circ}$ andar bloco D, sl.1001 • Tels.: +55 21 2334-4088/4087 • http://www.e-publicacoes.uerj.br/index.php/polemica/index http://www.labore.uerj.br • laboreuerj@yahoo.com.br 
importam, como formas de viver que contam como "vida", como vidas que valem a pena proteger, como vidas que valem a pena salvar, como vidas pelas quais valem a pena chorar. Tudo que está na abjeção não cabe na matriz heterossocial ${ }^{2}$ e é aquilo que tenciona, perturba e modifica o padrão da lógica cisheterossexista ${ }^{3}$.

Patrícia Porchat (2007) analisa a postura teórica de Butler, a recusa de uma concepção de Édipo clássica, baseada na via da identificação. Ao direcionar sua crítica a Sigmund Freud, Lacan e Lévi-Strauss, simultaneamente, a filósofa mover-se-ia para uma posição que Porchat chama de enfrentamento generalizado da psicanálise. Butler manteria suas críticas dirigidas ao Freud e ao Lacan dos anos 1950, no momento da produção teórica do psicanalista francês no qual ele incorporava a noção de inconsciente, via Lévi-Strauss, e desenvolvia o "simbólico" na esteira do estruturalismo. Porchat adverte que Butler não investiga as possíveis consequências do "real" passar a ter precedência sobre o "simbólico" na construção lacaniana dos anos 1970. Porchat diz que mesmo entre os psicanalistas, muitos tampouco fazem esta leitura de Lacan, assim contribuindo para manter em suspenso a possibilidade de conceber um "simbólico" que,

[...] nas palavras de Butler, dê conta da complexidade de gênero em que sempre vivemos e permita àqueles que entendem seu gênero e seu desejo como não normativos possam viver e prosperar sem a ameaça de violência do mundo externo e sem o sentido de sua própria irrealidade, que pode levar ao suicídio ou a uma vida suicida. (PORCHAT, 2007, on-line).

$\mathrm{Na}$ discussão do desvio de padrões, Monique Wittig (2006) fornece uma interessante pista para subverter tal problema: a autora afirma que a categoria lésbica é o único conceito em sua visão que está para além das categorias de sexo (mulher e homem), já que o sujeito designado lésbica não seria considerado uma mulher nem economicamente, nem politicamente, nem ideologicamente. Na esteira do pensamento de Rubin (1993), Wittig (2006) defende que o que constitui uma mulher é sua relação social específica com um homem, uma relação que no

\footnotetext{
2 Possuindo linhagens na noção de Gayle Rubin (1993) do "sistema sexo/gênero" e na ideia de Adrienne Rich de heterossexualidade compulsória (apud ARÁN, 2016), e sendo concebido para descrever as normas contra as quais as pessoas não-heterossexuais lutam, o termo heteronorma rapidamente incorporou-se aos debates de gênero e em discussões feministas. Por exercer o poder de ratificar, na cultura, a compreensão de que a norma e o normal são as relações existentes entre pessoas de sexos diferentes, o conceito refere-se ao dispositivo histórico da sexualidade (FOUCAULT, 1985) que deve formar todos para serem heterossexuais ou organizarem suas vidas a partir do modelo supostamente "natural" da heterossexualidade.

${ }^{3}$ Supervalorização da heterossexualidade em detrimento das outras formas de orientação sexual. O heterossexismo se insere na sociedade por meio das leis, religiões, políticas públicas, políticas curriculares (currículo real ou currículo oculto nas escolas), por meio dos costumes, da língua e da linguagem, entre outros, buscando ocultar a diversidade sexual presente na sociedade, especialmente no âmbito escolar (ROCHA FILHO, 2010).
}

\section{POLÊM!CA | LABORË:}

Polêmica - Revista Eletrônica da Uerj - Rua São Francisco Xavier, 524, $1^{\circ}$ andar bloco D, sl.1001 • Tels.: +55 21 2334-4088/4087 • http://www.e-publicacoes.uerj.br/index.php/polemica/index http://www.labore.uerj.br • laboreuerj@yahoo.com.br 
patriarcado veste-se da alcunha de servidão, uma relação demarcada por obrigações pessoais, físicas e econômicas (como, por exemplo, os trabalhos domésticos, deveres conjugais, produção de filhos, etc.). A essa relação, as lésbicas escapam quando rejeitam ser ou continuar sendo heterossexuais. Poderíamos aproximar essas reflexões da população T? É uma aproximação complexa, pois algumas pessoas trans, travestis e intersexo almejam conseguir se enquadrar nas regras que definem e permitem um reconhecimento para além da abjeção. Seria uma potência de agência política da existência não se enquadrar?

Assim como os traidores de gênero (ATWOOD, 1985), lésbicas como Monique Wittig são desertoras da classe mulher. Wittig (2006) faz analogia dessa condição com a de pessoas escravizadas nos Estados Unidos, quando escapavam da escravidão e se tornavam livres. Para a autora, esta é uma necessidade absoluta; a sobrevivência da lésbica exige que se dediquem a destruir essa classe, e isso só pode ser alcançado por meio da detonação da heteronorma, enquanto um sistema social baseado na opressão de mulheres e de homens, um sistema que produz o corpo e produz doutrinas da diferença entre os sexos para justificar a própria opressão.

\section{Considerações finais}

A reflexão da abjeção em Bento, Kristeva e Butler limitou-se, até aqui, na seara da violência enquanto emergência de uma angústia pré-simbólica frente à fissura na certeza do sexo/gênero que as figuras tidas como abjetas estampam. Contudo, deparamo-nos com uma reflexão sobre o apagamento - enquanto consequência da abjeção - dos corpos trans na arte. Há uma produção incessante de falas e discursos sobre os corpos travestis, transexuais, transgêneros e intersexos, mas essa fala é sempre cisgênera e solitária. Ela não chama para si a companhia de corpos abjetos. "Vão querer continuar fingindo que a gente não existe, que isso aí não é a vida que existe pra nós? " (MOIRA, 2016, p. 113).

Tomamos a liberdade de, para ilustrar o argumento acima, transpor a fala da Atriz Renata Carvalho, travesti e ativista, publicada em seu perfil do Facebook (CARVALHO, 2018). Atualmente Renata milita pelo movimento "Representatividade Trans Já - Diga sim ao talento Trans" contra o Fake Trans, nas artes, evidenciando a prática como um apagamento das pessoas Ts e intersexo nas produções artísticas em geral:

TIME'S UP - Acabou o Tempo

Oprah Winfrey / Globo de Ouro / Representatividade Trans / Trans Fake.

\section{POLÊM!CA | LABORE}

Polêmica - Revista Eletrônica da Uerj - Rua São Francisco Xavier, 524, $1^{\circ}$ andar bloco D, sl.1001 • Tels.: +55 21 2334-4088/4087 • http://www.e-publicacoes.uerj.br/index.php/polemica/index http://www.labore.uerj.br • laboreuerj@yahoo.com.br 
Olá Cisgêneros, agora desbloqueada (sim fui bloqueada por $24 \mathrm{~h}$ aqui no Feyce) não param de aparecer na minha timeline gente cisgênera, desconstruída, atenta, branca, que super apoia o movimento LGBT, de esquerda, feministas e artistas todes (sem exceção e concordo) emocionadíssimos, alguns ovacionando (com toda razão) o discurso que Oprah deu no último domingo dia 07, no Globo de Ouro.

Oprah é a primeira mulher negra a ganhar o Globo de Ouro honorário, o prêmio Cecil B. Mille, o troféu celebra o conjunto da obra artística.

Voltando ao discurso da Oprah tão louvado pelos artistas "cisgêneros desconstruídos "MAS eu queria avisar que não vale achar lindo, de chorar o discurso dela nos EUA e apoiar no Brasil o Trans Fake viu? (Ah, não se posicionar também viu querides).

Ou vocês "artistas cisgêneros apoiadores da causa LGBts" acham que a Oprah falava sobre o que quando diz:

"Em 1964, eu era uma garotinha sentada no chão de linóleo da casa da minha mãe em Milwaukee, assistindo Anne Bancroft entregar o prêmio de melhor ator na $36^{\circ}$ edição do Oscar. Ela abriu o envelope e disse 5 palavras que literalmente fizeram história: ' $O$ vencedor é Sidney Poitier'. Subiu ao palco o homem mais elegante que eu jamais havia visto. Lembro que a gravata era branca, e é claro que sua pele era negra. Eu nunca tinha visto um homem negro ser celebrado daquela forma..."

Neste momento Oprah, ainda menina olhando aquela TV, se viu REPRESENTADA. E continua:

"Muitas, muitas, muitas vezes tentei explicar o que um momento como aquele significa para uma garotinha..."

Nós também estamos aqui Oprah tentando muitas, muitas, muitas vezes explicar o que significa ser e se sentir REPRESENTADA. E prossegue:

"Neste momento, há garotinhas (como ela foi) vendo eu me tornar a primeira mulher negra a receber este mesmo prêmio. É uma honra e privilégio dividir esta noite com todas elas..."

Oprah no seu discurso quer ser a REPRESENTAÇÃO/ a REPRESENTATIVIDADE para aquelas garotinhas que estavam à assistindo na TV, como eu um dia assisti Phedra de Cordoba sendo entrevistada pelo Jô Soares, naquele momento eu disse para mim mesma: É POSSIVEL.

Na mesma noite, Natalie Portman quando foi entregar o prêmio de melhor direção ela diz:

"Aqui estão os indicados, TODOS homens"

Adivinhem sobre o que ela estava falando: REPRESENTATIVIDADE. Pois ela (Natalie) e todas as outras MULHERES, não estavam sendo REPRESENTADAS pois havia APENAS indicados HOMENS. Isso meus amores chama-se: REPRESENTATIVIDADE.

Então vamos globalizar a desconstrução? Não vale ser desconstruíde só quando está no Aeroporto Internacional de Guarulhos viu.

REPRESENTATIVIDADE é o ato de estar PRESENTE.

Outra querides vamos despersonalizar esta luta? Não estamos brigando contra o Luís Lobianco, Silvero Pereira ou seja lá quem for. Estamos brigando contra a estrutura que nega esses corpos TRANS nessas peças, naquela novela, naquele filme, naquela outra peça, naquela serie, naquela outra peça... e assim vai.

Outro ato que chamou muito a atenção foi o fato das mulheres irem todas vestidas de preto, em protesto aos abusos dos homens de cinema (esse lugar de homem, branco, cis, elitista e classista). Isso significa SORORIDADE, fortalecimento e união para mudar algo estrutural. E sabe por que aquelas mulheres fizeram e estão fazendo isso? $\mathrm{Pq}$ juntas elas perceberam que são muito mais fortes. Uma mulher chegar em uma premiação e olhar para outra mulher também vestida de preto é dizer e sentir: Estamos juntas nessa, não vamos nos calar".

Volto a DIVA Oprah Winfrey que termina seu discurso dizendo:

"Neste ano nós nos tornamos a história. Mas não é uma história que afeta apenas a indústria do entretenimento. Ela transcende qualquer cultura, geografia, raça, religião, política ou local de trabalho."

\section{POLÊM!CA $\mid$ LABORE}

Polêmica - Revista Eletrônica da Uerj - Rua São Francisco Xavier, 524, $1^{\circ}$ andar bloco D, sl.1001 • Tels.: +55 21 2334-4088 / 4087 • http://www.e-publicacoes.uerj.br/index.php/polemica/index http://www.labore.uerj.br • laboreuerj@yahoo.com.br 


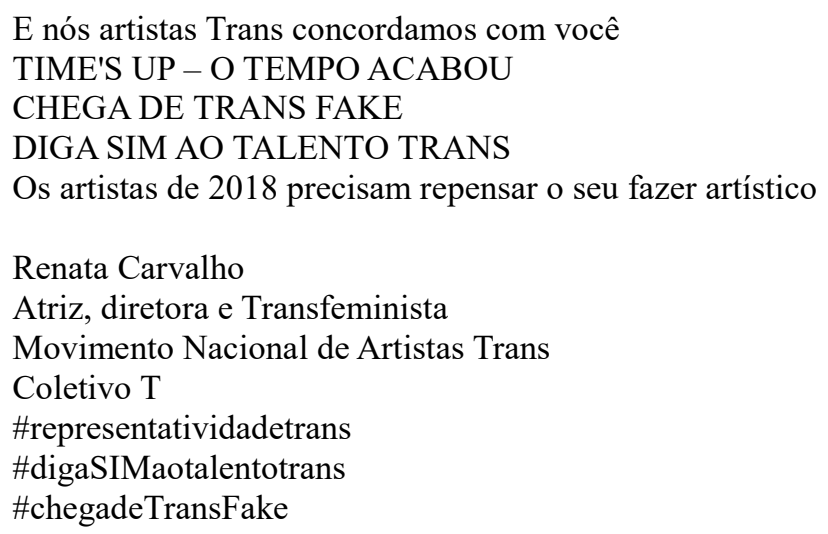

O que Renata faz aqui é uma corajosa denúncia. O que ela luta é por uma saída da abjeção profissional. Especialmente pela fetichização das narrativas trans, travestis, transgêneras e intersexo. Uma exploração dessas vivências sem o protagonismo de quem é responsável por vivenciá-las. O caso da peça do CCBB (FIORATTI, 2018) no mês da visibilidade trans sem que haja nenhuma pessoa $\mathrm{T}$ ou intersexo é um claro exemplo.

Retomando o que Jacqueline de Jesus defende (2013), a possibilidade de alcançarmos uma direção na qual uma pessoa assumir-se e vivenciar uma identidade trans ou travesti, ou intersexo ou transgênera, sem que ela seja abjeta, só é possível por meio da mobilização social, por protagonismo dos grupos sociais marginalizados, em que as pessoas que vivenciam as transgeneridades (ou transgeneralidades), orientadas por políticas de identidade, tornem a sua realidade cada vez mais visível por meio de muita luta "dentro dos sistemas legais e políticos, para propiciar um maior reconhecimento de sua humanidade e da justeza de suas várias demandas. Dentre elas, o direito à identidade, e antes desta, o direito à vida" (JESUS, 2013, p. 119).

\section{Referências}

ABREU, Felipe. Travesti é morta com tiro no rosto em ponto de prostituição em Macapá, diz PM. 2017. G1, Macapá, 30 out. 2017. AP. Disponível em: <https:/g1.globo.com/ap/amapa/noticia/travesti-e-morta-com-tiro-norosto-em-ponto-de-prostituicao-em-macapa-diz-pm.ghtml>. Acesso em: 07 jan. 2018.

ARÁN, Márcia. A transexualidade e a gramática normativa do sistema sexo-gênero. Ágora, Rio de Janeiro, v. 9 , n. 1, p. 49-63, jun. 2006. Disponível em: http://www.scielo.br/pdf/agora/v9n1/a04v9n1.pdf. Acesso em: 22 fev. 2016.

ANTRA. Mapa dos assassinatos. Mapa 2019. Antra, 2019. Disponível em: https://antrabrasil.org/mapadosassassinatos/. Acesso em: 06 jan. 2018.

ATWOOD, Margaret. The Handmaid's Tale. Londres: Virago Press, 1985.

\section{POLÊM!CA $\mid$ LABORE}

Polêmica - Revista Eletrônica da Uerj - Rua São Francisco Xavier, 524, $1^{\circ}$ andar bloco D, sl.1001 • Tels.: +55 21 2334-4088 / 4087 • http://www.e-publicacoes.uerj.br/index.php/polemica/index http://www.labore.uerj.br • laboreuerj@yahoo.com.br 
BALZER, Carsten; LaGATA, Carla; BERREDO, Lukas. TMM anual report 2016. Berlin: TGEU Transgender Europe, 2016. (TvT Publication Series, v. 14, Oct.). Disponível em: https://transrespect.org/wpcontent/uploads/2016/11/TvT-PS-Vol14-2016.pdf. Acesso em: 20 out. 2017.

BENTO, Berenice. A reinvenção do corpo: sexualidade e gênero na experiência transexual. Rio de Janeiro: Garamond, 2006.

Transviad@s: Gênero, sexualidade e direitos humanos. Salvador: EDUFBA, 2017.

BONFIM, Flávia. Todo fálico e não-todo: construções lacanianas sobre a sexuação. Estudos e Pesquisas em Psicologia, Rio de Janeiro, v. 14, n. 1, p. 201-213, 2014. Disponível em:

http://www.epublicacoes.uerj.br/index.php/revispsi/article/view/10476/8248. Acesso em: 25 jan. 2018.

BUTLER, Judith. Corpos que pesam: sobre os limites discursivos do "sexo". In: LOURO, Guacira Lopes (Org.). O corpo educado: pedagogias da sexualidade. Belo Horizonte: Autêntica, 2000. p. 151-176.

2013.

Problemas de gênero: feminismo e subversão da identidade. Rio de Janeiro: Civilização Brasileira,

CATÃO, Priscila de Lima. A Fórmula da Sexuação e a Teoria de Gênero: algumas problematizações. In: XX congresso do Círculo Brasileiro de Psicanálise e XXXI Jornada de Psicanálise do Círculo Psicanalítico de Minas Gerais. 20/31, 2013, Minas Gerais. Anais. Belo Horizonte: Circulo Brasileiro de Psicanálise, 2013. Disponível em: <http://www.cbp.org.br/36.pdf>. Acesso em: 25 jan. 2015.

CARVALHO, Renata. TIME'S UP - Acabou o Tempo. Facebook. 9 jan. 2018. Disponível em: https://www.facebook.com/renatacarvalhoteatro/posts/2436403193057540?pnref=story.unseen-section. Acesso em: 10 jan. 2018.

FANON, Frantz. (1952). Pele negra, máscaras brancas. Salvador: EDUFBA, 2008.

FOUCAULT, Michel. A História da Sexualidade III: O Cuidado de Si. São Paulo: Edições Graal, 1985.

FREUD, Sigmund (1905). Três ensaios sobre a teoria da sexualidade In: Edição Standard Brasileira das Obras Psicológicas Completas de Sigmund Freud, Vol. 7. Rio de Janeiro: Imago, 1969. p. 119-218.

FIORATII, Gustavo. Movimento de travestis e transexuais ataca ator que faz trans em peça. Folha de São Paulo, São Paulo, 11 jan. 2018. Disponível em: https://www1.folha.uol.com.br/ilustrada/2018/01/1949679-movimentode-travestis-e-transexuais-ataca-ator-que-faz-trans-em-peca.shtml. Acesso em: 6 jan. 2019.

GONÇALVES JR, Sara Wagner Pimenta. Morte Anunciada: Reflexões de uma mulher travesti sobre o assassinato de Dandada. In: JESUS, Danie Marcelo de; et al. Corpos transgressores: Politicas de resistências. Campinas: Pontes, 2018. p. 17-23.

JESUS, Jacqueline Gomes. Orientações sobre a população transgênero: conceitos e termos. Brasília: Autor, 2012. Disponível em: http://issuu.com/jaquelinejesus/docs/orienta_es_popula_o_trans. Acesso em: 12 mar. 2017.

Transfobia e crimes de ódio: Assassinatos de pessoas transgênero como genocídio. História Agora, v.

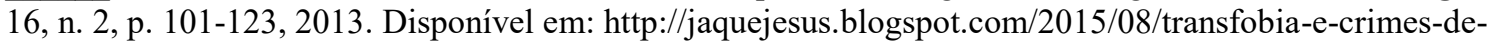
odio.html. Acesso em: 25 out. 2018.

KRISTEVA, Julia. Powers of horror: An Essay of Abjection. New York: Columbia University Press, 1982.

LACAN, Jacques (1966). O estádio do espelho como formador da função do eu. In: Janeiro: Zahar, 1998. p. 96-103.

Escritos. Rio de

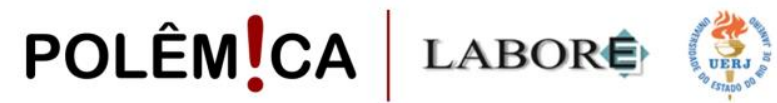

Polêmica - Revista Eletrônica da Uerj - Rua São Francisco Xavier, 524, $1^{\circ}$ andar bloco D, sl.1001 • Tels.: +55 21 2334-4088 / 4087 • http://www.e-publicacoes.uerj.br/index.php/polemica/index http://www.labore.uerj.br • laboreuerj@yahoo.com.br 
LACAN, Jacques (1972-73). O Seminário 20 - mais, ainda. Rio de Janeiro: Jorge Zahar Editor, 1985.

MADEIRO, Carlos. ONG aponta recorde de LGBTs mortos no Brasil em 2017; "dói só de lembrar", diz parente. UOL, Maceió, 25 set. 2017. Disponível em: https://noticias.uol.com.br/cotidiano/ultimasnoticias/2017/09/25/brasil-tem-recorde-de-lgbts-mortos-em-2017-ainda-doi-diz-parente.htm?cmpid=copiaecola. Acesso em: 07 jan. 2018.

MOIRA, Amara. E se eu fosse puta. São Paulo: Hoo, 2016.

NETO, Amauri Garcia Santos. Abjeção Autobiográfica: Francis Xavier Enderby como dejeto de Anthony Burgess. In: Anu. Lit., Florianópolis, v. 18, n. 1, p. 65-83, 2013. Disponível em: https://periodicos.ufsc.br/index.php/literatura/article/view/2175-7917.2013v18n1p65. Acesso em: 25 out. 2018.

PORCHAT, Patrícia. Respirar, desejar, amar e viver - A luta contra normas que restringem as condições básicas da própria vida. Revista cult, São Paulo, 2007. Disponível em: https://revistacult.uol.com.br/home/respirardesejar-amar-e-viver/. Acesso em: 10 jan. 2018.

QUINET, Antônio. A escolha do sexo com Freud e Lacan. In: QUINET, Antônio; JORGE, Marco Antônio Coutinho. (Org.). As Homossexualidades na psicanálise - na história de sua despatologização. São Paulo: Segmento Farma, 2013. p. 131-140.

ROCHA FILHO, João Silva. O currículo escolar e as relações de heterossexismo e homofobia na educação básica. In: Fazendo Gênero 9. 23-26 ago. 2010, Universidade Federal de Santa Catarina. Anais. Santa Catarina, 2010. Online. Disponível em:

http://www.fazendogenero.ufsc.br/9/resources/anais/1278293297_ARQUIVO_OCURRICULOESCOLAREASR ELACOESDEHETEROSSEXISMOEHOMOFOBIANAEDUCACAOBASICA.pdf. Acesso em: 25 out. 2018.

RUBIN, Gayle. O Tráfico de mulheres: notas sobre a “economia política” do sexo. Recife: SOS Corpo, 1993.

SPIVAK, Gayatri Chakravortry. Pode o Subalterno Falar? Belo Horizonte: Editora UFMG, 2010.

TWEETS ANTIGOS BIEL. Que nojo de travesti pelado, sério. 1 ago. 2016. Twitter: @antigosMcBiel. Disponível em: https://twitter.com/antigosMcBiel/status/760275069713149952. Acesso em: 09 jan. 2017.

VERGUEIRO, Viviane. Por inflexões decoloniais de corpos e identidades de gênero inconformes: uma análise autoetnográfica da cisgeneridade como normatividade. 2015. 244 f. Dissertação (Mestrado em Cultura e Sociedade) - Instituto de Humanidades, Artes e Ciências Professor Milton Santos, Universidade Federal da Bahia, Salvador, 2015.

WITTIG, Monique. El pensamiento heterosexual y otros ensaios. Madrid: EGALES, 2006.

YAHOO. Transei com um travesti e sinto nojo de mim mesmo. O que fazer ??? Yahoo! Respostas, 2014. Disponível em: https://br.answers.yahoo.com/question/index?qid=20141113005845AAhAbLp. Acesso em: 09 jan. 2017.

Recebido em: 30/01/2019.

Aceito em: 30/03/2019.

\section{POLÊM!CA $\mid$ LABORE}

Polêmica - Revista Eletrônica da Uerj - Rua São Francisco Xavier, 524, $1^{\circ}$ andar bloco D, sl.1001 • Tels.: +55 21 2334-4088 / 4087 • http://www.e-publicacoes.uerj.br/index.php/polemica/index http://www.labore.uerj.br • laboreuerj@yahoo.com.br 